\title{
Reflexões sobre a ecologia e as poéticas de um desvio
}

\author{
Reflections on Ecology and the Poetics of a Veering \\ Reflexiones sobre ecología y las poéticas de una desviación
}

Léo Karam Tietboehl (Universidade Federal do Rio Grande do Sul, Brasil) *

https://doi.org/10.22409/poiesis.v21i36.41024

\begin{abstract}
RESUMO: Este artigo pretende pensar as aproximações entre os desvios de uma poética e uma proposição ecológica. Para tanto, se utiliza do conceito de escuta, refletindo sobre as reverberações desta em um corpo, a partir da experiência de um poema e de suas ressonâncias afins ao funcionamento de um eco.
\end{abstract}

PALAVRAS-CHAVE: ecologia; poesia; desvio

\footnotetext{
* Léo Karam Tietboehl é psicólogo, mestre pelo Programa de Pós-Graduação em Psicanálise - Clínica e Cultura (UFRGS) e membro do Laboratório de Pesquisa em Psicanálise, Arte e Política (LAPPAP/UFRGS), da Utopian Studies Society e do Grupo de Pesquisa e Ecologia das Práticas (APPH). E-mail: leokt2@gmail.com. Orcid: https://orcid.org/0000-0003-2416-6649
} 
ABSTRACT: This article aims to think about the approximations between the veering of a poetics and an ecological proposition. For that, it uses the concept of listening, reflecting on the reverberations of it in a body, from the experience of a poem and its resonances related to the functioning of an echo.

KEYWORDS: ecology; poetry; veering

RESUMEN: Este artículo pretende pensar en las aproximaciones entre las desviaciones de una poética y una proposición ecológica. Para esto, utiliza el concepto de escucha, reflexionando sobre las reverberaciones de este en un cuerpo, a partir de la experiencia de un poema y sus resonancias relacionadas con el funcionamiento de un eco.

PALABRAS CLAVE: ecología; poesía; desviación

Citação recomendada:

TIETBOEHL, Léo Karam. Reflexões sobre a ecologia e as poéticas de um desvio. Revista Poiésis, Niterói, v. 21, n. 36, p. 263-284, jul./dez. 2020.

[https://doi.org/10.22409/poiesis.v21i36.41024]

(cc) BY-NC-ND

Este documento é distribuído nos termos da licença Creative Commons Atribuição-NãoComercial 4.0 Internacional (CC-BY-NC) (c) 2020 Léo Karam Tietboehl 


\section{Reflexões sobre a ecologia e as poéticas de um desvio}

A deriva, técnica artística e política de experimentação da urbe esboçada coletivamente em 1958 pelo movimento da Internacional Situacionista, toma como elemento chave o caminhar cujo rumo não preexiste antes de seu acontecimento possibilitando, ao funcionar desta maneira, a descoberta e a criação de espaços em uma paisagem urbana. Guy Debord, tomado como referência dessa proposta, observa:

\footnotetext{
Em uma deriva, uma ou mais pessoas renunciam durante certo período a suas relações, a suas atividades de trabalho e leitura - bem como a seus motivos usuais para movimentar-se e agir-; $\mathrm{e}$ deixam-se tomar pelas atrações do território e
}

\author{
pelos encontros que se dão neste contexto. 0 \\ aleatório é um fator menos importante nessa ati- \\ vidade do que se poderia imaginar: desde um \\ ponto de vista da deriva, as cidades têm contor- \\ nos psicogeográficos de correntes constantes, \\ pontos fixos e vórtexes que contraindicam forte- \\ mente a entrada ou a saída de algumas zonas. \\ (DEBORD, 1958, p. 59, tradução livre)
}

Muito mais do que um simples deixar-se levar, trata-se, nestes procedimentos, de buscar um caminhar atento às possibilidades de desvio e aos fatores que subrepticiamente operam em uma cidade ${ }^{1}$. Sugere-se ao itinerante em deriva que direcione seu olhar à meia-altura e estabeleça, no contexto em que colocar sua ativi- 
dade, alguns elementos norteadores deste percurso. A aposta é a de que tais elementos, quando escolhidos por um conjunto de fatores contingencial, podem surtir um efeito desnorteante, fazendo entrever a um olhar que não mais se adequa a um plano do costumeiro, no qual os elementos da cidade, ainda que desapercebidos, operam de uma forma ou de outra na maneira como a urbe se movimenta.

Mas podemos tomar a ideia de deriva por uma definição maior do que a do método proposto pela Internacional Situacionista. singular de habitar a cidade, a palavra derivar designa também $o$ ato de promover um desvio - seja de um processo de percurso, ou de um encadeamento determinado, ou do olhar. Pelo desvio pode-se perceber aquilo que "já estava lá" e que não se evidenciava antes deste mesmo desvio.

Como Debord afirma, em uma deriva não se trata de propor um jogo suscetível e capturado, apenas, pelas intromissões aleatórias do acaso. Em função de uma disposição à mudança de perspectiva e de sentido (e aqui escolho colocar esta pala-

Léo Karam Tietboehl, Reflexões sobre a ecologia e as poéticas de um desvio. aos sentidos de um percurso quanto aos de uma significação), a deriva aposta no desvelamento dos elementos que estavam, desde pronto, colocados em cena mas que não tinham sido percebidos até um momento de encontro, de experiência singular ${ }^{2}$. 
soltar a palavra

da boca,

envio

em desvio

qualquer coisa

qualquer

que registre

\section{(pelo menos \\ resiste)}

palavra solta

salta

atenta

flutua

(nonada). 
à espera,

a escuta

deixa

perceber

a imagem que

diante do olhar,

só-depois,

faz ver que

já-antes

algo se fazia

268

quase-pronto

(só que

ainda-não).

trata-se

aqui, agora

de furar a forma

abrir abismos

entre o que é

e o que poderia ser 
(será que o que será

era pra ser,

no fundo,

o que antes

se disse que

seria?)

\author{
aqui, agora \\ pouco importa \\ o quando; \\ importa que \\ algo \\ foi
}

\author{
(algo, \\ entretanto, \\ registrarei)
}


e que

qualquer coisa

agora

é.

$$
\begin{gathered}
\text { (al fin } \\
y \text { al cabo) }
\end{gathered}
$$

trata-se

da luta

(eterna

luta)

pela sobrevivência, contra

a impiedade de chronos

contra

a distância

que mostra

que não há encontro

Léo Karam Tietboehl, Reflexões sobre a ecologia e as poéticas de um desvio. 
(nunca há

encontro)

trata-se

de enfrentar

o fracasso

saber esperar

perder

(mesmo assim
tentar
chegar
perto)

e entender

que só se perde

porque o que era

é agora

outra coisa 
Para que se possa experienciar um poema é necessário habitá-lo, durante certo tempo; e então perceber suas amarrações e conectar seus elementos por uma arbitrariedade que, ao longo deste processo de associação, mostra o seu sentido. Por estas razões a deriva interessa a este trabaIho: pelo jogo que faz, inextrincavelmente, entre o sentido e o arbitrário; assim como pelas relações que se podem estabelecer quando um corpo se coloca à deriva, em campo. Ainda, a deriva nos interessa pela sua relação com o espaço, no tempo, através de um caminhar.

Para derivar, ou para que se experiencie um poema, é necessária certa escuta ao que não salta aos olhos - mas que inevitavelmente está presente. Aqui podemos lembrar do que Sigmund Freud coloca ao dizer do infamiliar (2019 [1930]) - isso que parece estranho, mas cuja percepção em si diz, já, de algo muito íntimo. O psicanalista coloca, por este e outros textos, as pistas de um processo de escuta a ser retomado por Jacques Lacan (1998 [1956]), quando este se dedica a pensar a mensagem como um mediador, desviante, das relações entre emissor e destinatário.
Há algo, neste jogo de mediação, que remete ao funcionamento de um eco. Em termos práticos, o eco consiste em uma reflexão do som, a qual chega à percepção de um receptor com certo atraso em relação ao som inicialmente produzido. Desnecessário talvez será lembrar que, no funcionamento do eco, este que é o receptor do som refletido era, também, o emissor deste mesmo som, antes da sua reflexão. O fenômeno, neste contexto, parece relacionado a um encontro com um outro em si.

Não se trata, portanto, quando pensamos por essa via, de dizer de uma escuta apenas do que surge, mas também de seus ecos; das ressonâncias desta em um corpo que, a partir da escuta, vibra e se desloca. Serve o corpo de que se fala aqui sendo talvez irrelevante neste momento se sua condição é pessoal, teórica, narrativa ou de significantes - para que tome lugar, nesta análise, a dimensão perceptiva daquilo que, desde um ato ou gesto, retorna por uma condição já diferente.

A este ponto podemos associar, em primeiro lugar, uma maneira poética e disposta à escuta - a qual, conforme Jean- 
Luc Nancy (2002) destaca, dedica-se a perceber as ressonâncias que se fazem, como em um funcionamento de eco, de si a si. Ainda, a uma maneira que trabalha a partir de uma ecologia, disponível a perceber as reverberações de sua prática cuja localização ou balizamento são incertos e, por este motivo mesmo, surpreendente.

Este termo, ecologia, tem origem relativamente recente, apesar de referenciar e nomear práticas que, nas interpretações de hoje, antecedem sua gênese. Os diversos usos do conceito, que decorrem desde o século XIX, momento em que os escritos do cientista Ernst Haeckel (1866) o registram oficialmente, referem-se a uma maneira de entender que exige, desde pronto, certa interdisciplinaridade. Dos vários referenciais que podemos citar para explicar a ideia de ecologia, assumimos o trabalho de Félix Guattari como aquele que parece aproximar mais este conceito ao que se quer dizer aqui. Em As Três Ecologias (2001 [1989]), o filósofo e psicanalista parte de uma análise multifacetada da realidade em que escreve para fazer a proposta de uma ecosofia, que torna perceptíveis as relações intrínsecas entre as dimensões de uma leitura do mental, de um contexto social e de um meio ambiente $^{3}$. Como síntese da sua lógica, o autor dirá:

\section{Fazer emergir outros mundos diferentes daquele da pura informação abstrata; engendrar Univer- sos de referência e Territórios existenciais, onde a singularidade e a finitude sejam levadas em con- ta pela lógica multivalente das ecologias mentais e pelo princípio de Eros de grupo da ecologia so- cial e afrontar o face a face vertiginoso com 0 Cosmos para submetê-lo a uma vida possível — tais são as vias embaralhadas da tripla visão eco- lógica. (GUATTARI, 2001 [1989], p. 52-53)}

Indo por estas vias, podemos inferir que trabalhar com as perspectivas do conceito de ecologia nos leva além de uma noção simplificada - relacionada, por exemplo, a um meio ambiente restrito às condições ecossistemáticas, de uma biodiversidade e nos direciona a que, de certa maneira, percebamos a complexidade inapreensível das conexões subterrâneas que este campo pode estabelecer. Isto é dizer: há uma exigência, aí, a que percebamos mesmo as condições deste meio ambiente enquanto algo que advém do contato com as outras instâncias que aí se intrometem. 
Isso reivindica que, quando tratamos sobre uma ecologia, ainda que estejamos nos domínios de um meio ambiente, não a tomemos de maneira restrita e puramente biológica, conforme se poderia depreender a partir de uma leitura hegemonicamente estabelecida. Tal ideia fica mais presente no trabalho de Bruno Latour, intitulado Políticas da Natureza (2004 [1999]), em que o autor pretende estabelecer relações, em um mesmo plano, entre os termos oikos, logos, physis e polis. Ao trabalhar a partir de uma ecologia (oikos + logos), Latour mostra a inevitável relação entre as dimensões de uma natureza (physis) e de uma política (polis), muito em diálogo com suas produções anteriores a respeito de uma inventada modernidade (1994 [1991]). Neste outro momento, Latour tomará a política e a ciência não enquanto instâncias simétricas, mas consubsistentes e inseparáveis, que se confundem a ponto de ser impossível, por exemplo, determinarmos a essencialidade de uma Ciência ${ }^{4}$. Neste ponto surge a importância de uma ecologia que, pela dimensão lógica que traz consigo, sabe ser um estudo fadado a uma dimensão dos fatos, mas, também, de valores: ambos termos de que o autor se utiliza com o intuito de fazer perceptí- vel também sua inseparabilidade - já que mesmo uma descrição de fatos carrega, consigo, uma dimensão moral e normativa: "o que é define o mundo comum e, portanto, tudo o que deve ser". (LATOUR, 2004 [1999], p. 363, grifos do autor) Mais além, Latour conclui:

\section{Todas as -logias, -grafias, -nomias, tornam-se então indispensáveis, prestam-se a propor cons- tantemente ao coletivo novas versões do que po- deria ser [...]. A ecologia política marca a idade de ouro das ciências sociais, libertadas, enfim, do modernismo. (2004 [1999], p. 365)}

A relevância deste conceito se refere, para o autor, mais a uma consideração do fracasso que se segue a qualquer tentativa de apresentação neutra de uma instância - o qual comumente uma ciência comprometida com certos ideais de uma paradigmática procura "superar", supondo este um horizonte alcançável.

É neste sentido que a ecologia que se trabalha aqui é colocada pela via de uma incerteza e de, conforme já vimos, de um fracasso. Latour dedica a produção do livro supracitado à Isabelle Stengers - que, também em uma via conforme a que to- 
mamos aqui, constrói um pensamento sobre a ecologia e a poesia em um texto breve e instigante chamado $A$ proposição cosmopolítica (2018 [2007]). Ali, a autora retoma algumas ideias de uma ecologia política para salientar as potências de um saber que se autoriza, à revelia de certa expertise científica, a se construir de maneira pública e coletiva, a partir de implicações constituídas no valor de sua singularidade. Proposição esta que harmoniza ao que, em outros textos, Stengers nos dirá através da ideia de uma ecologia das práticas - e que encontra um personagem conceitual na figura do idiota. Para Stengers, o idiota seria como um mediador que oferece um interstício aos modos de um saber que se possa supor já estabelecido. Ela dirá, sobre o primeiro:

\section{sua eficácia não está em desfazer os fundamen- tos dos saberes, em criar uma noite onde todas os gatos são pardos. Nós sabemos, existem saberes, mas o idiota pede que não nos precipitemos, que não nos sintamos autorizados a nos pensar de- tentores do significado daquilo que sabemos. (STENGERS, 2018 [2007], p. 444)}

Trilhando estes caminhos, a cosmopolítica, na maneira como Stengers a constrói, pa- rece querer nos dizer que nosso agir tem repercussões - nem sempre visíveis - em contextos que escapam às possibilidades da nossa compreensão. Para a autora, portanto, há certa problemática a partir daí, sendo uma tarefa delicada a de fazer legítimas as produções discursivas de um saber que não se encontra formalizado nos registros bem-estabelecidos de um statusquo - e que talvez por este motivo mesmo tome sua importância. Estes saberes, a pensadora os caracteriza enquanto um sussurro, proferido pelo idiota e cuja percepção requer uma disposição à atenção.

Ao chamar a atenção para certa posição de escuta aos registros das dimensões aparentemente secundárias de um saber (mas que assim se leem justamente em função de certa hegemonia situada de acordo com a arbitrariedade de algumas convenções), Stengers nos abre a possibilidade de estabelecer um paralelo - entre a premência dos reposicionamentos em uma sistemática aparentemente jáestabelecida (que se nos colocam pelas vias de uma cosmopolítica sustentada por uma ecologia) e as reinvenções que se podem fazer no campo de uma gramática, pela poesia. 
Pois se - conforme o que Stengers, junto a Pignarre, afirmará em outro momento (2005) - tomamos os meios de produção de um capitalismo enquanto uma sistemática que mostra seus pontos cegos pelas vias de uma pragmática (e cujas formas, inclusive algumas de uma ciência, se colocam já capturadas por certos moldes a serviço desta produção), podemos tomar os processos de escritura e de leitura de uma poesia para pensar os acontecimentos de enunciação ${ }^{5}$ que subvertem as sistemáticas já estabelecidas de uma gramática.
Ao não-saber que se coloca pela maneira de pensar uma ecologia poderíamos associar, consonantemente, o caráter de indecidibilidade do sentido de um poema. Nesta direção, retornemos aos dizeres de Guattari, quando fala sobre

\section{A ambiguidade, por exemplo, de um texto poéti- co que a um só tempo pode transmitir uma men- sagem, denotar um referente, funcionando es- sencialmente sobre redundâncias de expressão e conteúdo [...]. Também encontramos essa ecoló- gica operando na vida cotidiana, nos diversos pa- tamares da vida social e, de forma mais geral, a cada vez que está em questão a constituição de um Território existencial. (GUATTARI, 2001 [1989], p. 29)}

Pensemos um pouco mais sobre as potências destas conexões.

Em Linguística e Poética (2005 [1960]), Roman Jakobson fala sobre a função poética, conceitualizando esta como aquilo que se relaciona à própria mensagem entre um emissor e um receptor. Neste e em outros momentos (1978 [1976]), o autor estabelece a função poética nesta relação entre o som e o sentido, entre o seletivo e o combinatório, para salientar a potência 
que se apresenta, pela poesia, de dissociarem-se as associações a priori entre os elementos de um discurso e suas possibilidades de significação. Para além de uma dimensão informativa, à função poética creditaríamos, portanto, uma dimensão metalinguística, interpretante do contexto e que, por essa convocação a um fora da linguagem, inevitavelmente exige reestruturações à última.

O poético contradiz a ordem esperada, introduzindo elementos de desvio, atos ${ }^{6} \mathrm{cu}-$ ja relação com aquilo que atualizam ${ }^{7}$ é perceptível por esta atualização mesma. A função poética deixa ver a dimensão de acontecimento do que escapa à captura da linguagem e que, por este transbordamento, hackeia ${ }^{8}$ os códigos predefinidos de uma gramática - não raro por meio da mesma gramática. Permite, assim, que um desejo se diga - mas enquanto quase, porque no momento em que se diz é, já, outra coisa. Uma parte inaudita do discurso irrompe e se torna perceptível à medida que o ato, enquanto significante desviante, deixa um resto: faz perceber um quase-totalmente-significado, que serve de rastro ao que se produzirá depois - que ressignificará a identidade do que se colo- cou antes, e assim incessantemente ${ }^{9}$. O poético, neste jogo com o desejo, se aproxima do impossível pela via de uma tentativa, jogando exatamente com a falibilidade desta tarefa ${ }^{10}$.

Inevitável lembrarmos, neste momento, das colocações que Jacques Derrida (2013 [1967]) faz sobre a desconstrução. O autor situa este processo em conexão com uma poïesis e, de maneira análoga, a um desmonte: sem um método predeterminado que o caracterize de forma definitiva. Oferecendo mais pistas a respeito do que irrompe de maneira inédita e de suas potencialidades subversivas, Derrida (2007 [1980]) nos apresenta ainda o conceito de destinerrância, colocando-o como um endereçamento permeável ao desvio e comprometido com este de tal maneira que está fadado a não atingir, jamais, seu ponto final.

É possível concebermos o fim definitivo das possibilidades de significação de uma narrativa? 
lança-se a peça

o primeiro ato

os discursos em profusão

os corpos em mistura anômala

sem órgãos

\section{(toda peça}

é um pedaço

de tempo)

até

o intervalo entre o primeiro

e o segundo

atos

uma quebra

Léo Karam Tietboehl, Reflexões sobre a ecologia e as poéticas de um desvio. 
(seria esse

"meio"

o desvio?)

até

o novo início

dois

que só se sabe

pelo movimento

(atriz se move,

o olho captura)

toda trajetória

tem uma autoria

(o que move a autoria da trajetória?). 
Há sempre um resto, no dizer, que se evidencia e faz rastro no fracasso que se segue à tentativa de se situar. O poético brinca com estes elementos, propondo um jogo com o desejar ${ }^{11}$ ao deslocar aquilo que se pretendia da palavra antes de seu acontecimento. Propicia-se, pelo poético, não só um desvio de sentido, mas um sentido disposto ao desvio, porque se sabe fadado ao fracasso. Algo parecido com o dizer de uma palavra que espera pelas reverberações da mesma, em um intervalo de indecidibilidade sustentável pela lógica de um eco; pelas inevitáveis mudanças de

Espero terem ficado presentes, ao longo deste trabalho, as relações entre poesia e ecologia - as quais, penso, deve se dar mais pela via pragmática do que pela justificativa teorizada de sua existência. Por este motivo, encerro este texto aqui, apesar dos inúmeros deslindes que se poderiam seguir por estas letras desde essa associação.

\section{Notas}

${ }^{1} \mathrm{O}$ conceito de cidade aqui colocado pretende remeter a um sentido mais amplo do que aquele restrito ao de "espaço ao ar livre" ou "organização de uma malha urbana". Junto aos trabalhos de Palombini (2007) e Choay (1994), entendo este conceito buscando sua relação com a ideia de uma polis: palco ou arena de encontros, relações e confrontos.

${ }^{2}$ Lembremos por um instante das colocações de Saussure a respeito de uma arbitrariedade do signo (2012 [1970], p. 108-110) para afirmar que a relação entre o significante e o significado se estabelece sempre capturada por uma sistemática a partir da qual, pelas conexões como os outros elementos de um contexto, se determina um valor singular.

${ }^{3}$ Guattari procede esta diferenciação trabalhando, de maneira densa e contundente, cada uma das formas apresentadas. $\mathrm{O}$ autor, quando fala em uma ecologia mental, faz severas críticas em relação ao trabalho em conexão com as lógicas do capital e à maneira como alguns saberes "psi" referem-se ao inconsciente e à consciência, propondo reinvenções desta relação. Ao deter-se sobre uma ecologia social, Guattari retoma o primeiro ponto para nos direcionar à premência de que pensemos, desde aí, os aspectos pelos quais compomos nossas relações e constituímos os balizamentos de nossa sociedade. Neste ponto, o autor esclarece: "não se trata aqui de propor um modelo de sociedade pronto para usar, mas tão-somente de assumir o conjunto de componentes ecosóficos cujo objetivo será, em particular, a instauração de novos sistemas de valorização" (2001 [1989], p. 48-49). Neste sentido, o autor vai entender o ambiente também como sistemática produzida a partir deste tensionamento existencial, intermediado por temporalida-

Léo Karam Tietboehl, Reflexões sobre a ecologia e as poéticas de um desvio. 
des humanas e não-humanas. Ele dirá, encaminhando-se a um encerramento de seu escrito: "é exatamente na articulação: da subjetividade em estado nascente, do socius em estado mutante, do meio ambiente no ponto em que pode ser reinventado, que estará em jogo a saída das crises maiores de nossa época" (p. 55).

${ }^{4} \mathrm{O}$ autor usa a letra maiúscula para diferenciar esta de uma ciência à linha de um multinaturalismo que, consoante à proposta de Viveiros de Castro (2018 [2009]), entende a pluralidade de seus pontos de conexão e de suas perspectivas possíveis.

${ }^{5}$ Talvez ao invés de enunciações possamos dizer de proposições, junto a Latour (2004 [1999], p. 153), pensando estas para considerar os agenciamentos não-humanos neste processo.

${ }^{6}$ Intimamente ligado a tais conceitos, situo o que Jacques Lacan (2018 [1967-68]) nos coloca a respeito de um ato analítico. No contexto desta produção, o psicanalista amplia o conceito de ato ao tomar este como um desvio: uma operação que institui novos possíveis - e que, por este funcionamento mesmo, funda um fato ao ressignificar a identidade do conteúdo precedente. 0 psicanalista traz ainda os planos poético e sexual de um ato para dizer deste enquanto um acontecimento singular que altera uma cadeia de significantes sem rompê-la totalmente, mas desviando- $a$, mantendo uma conexão enquanto significante desviante. Pelo ato, há um movimento que acontece sem que sua instância operadora tenha um plano prévio sobre seus efeitos - tal movimento depende, invariavelmente, de uma instância outra que o reconheça, o inaugure e, assim, o complete.

${ }^{7}$ Gilles Deleuze (2011 [1968]) coloca, acerca dos processos de atualização e virtualização que o que é atual está em processo dialético com um virtual, que concerne ao campo do que não é realizado e tampouco realizável até o instante de sua atualização. A atualização, neste enredo, seria um processo de acontecimento do que se encontrava em um plano do virtual (e era imperceptível até então). Este acontecimento, por sua vez, modifica as propriedades do que é atual ao reconfigurar a identidade e as possibilidades desta instância, em um jogo com um processo de virtualização.

${ }^{8}$ A figura do hacker toma importância nesta intersecção entre poesia e ecologia por representar, em um contexto do contemporâneo, um operador do processo de denunciar, por sua forma singular e pragmática de operar, os problemas ou os pontos em que uma sistemática não cumpre de maneira total sua função. Diz-nos um grupo de autoria anônima: “A figura do hacker se opõe, ponto por ponto, à figura do engenheiro, quaisquer que sejam as tentativas artísticas, policiais ou empresariais de a neutralizar. Enquanto o engenheiro captura tudo o que funciona, e isso para que tudo funcione melhor a serviço do sistema, o hacker se pergunta 'como é que isso funciona?' para encontrar as falhas, mas também para inventar outras utilizações, para experimentar. Experimentar significa, então, viver o que implica eticamente esta ou aquela técnica. 0 hacker vem arrancar as técnicas do sistema tecnológico, libertando-as". (COMITÊ INVISÍVEL, 2016 [2014], p. 151). Indo nesta direção, podemos pensar em algumas considerações acerca do pragmatismo a partir das colocações de Stengers e Pignarre (2005) sobre as formas de leitura do sistema capitalista.

${ }^{9}$ Neste sentido, aproxima-se a psicanálise de um fazer poético a partir do que escreve René Passeron (2001) sobre uma poïanálise - sustentada em (e que joga com) o que irrompe de maneira inédita. 
10 Talvez seja propício relacionarmos essa tentativa à do personagem mitológico Ícaro, que se vê perdido e capturado ao labirinto de Creta junto ao seu pai, Dédalo - sendo o último responsável pela projeção e construção da maravilha arquitetônica, cuja infalibilidade se mostra ao superar as aptidões de seu próprio idealizador. A fim de sobrevoar esta estrutura e assim escapar de seus domínios, pai e filho montam asas a partir da cera de mel de abelha e de penas de pássaros diversos. Antes da jornada, ícaro é alertado por seu pai a que não voe muito próximo ao sol, ou ao mar, para que suas asas não se derretam ou se tornem pesadas. Sabemos do trágico fim dessa história, que se coloca pela via de um fracasso e da queda - e que serve aqui, talvez, para que pensemos aquilo que precipita do dizer.

${ }^{11}$ Em um seminário intitulado $A$ identificação (2018 [1960-61]), Lacan coloca o desejo e a demanda em paralelo, através da figura de dois toros, a fim de nos trazer a inacessibilidade entre um e outro. A última se coloca na superfície das formas representadas, enquanto aquilo que aparece; já o primeiro se mantém enquanto instância incapturável, cuja tradução em demanda compromete, já, qualquer fidedignidade àquilo que o constituía inicialmente. Buscando um paralelo entre as ideias de uma psicanálise e de uma esquizoanálise, possamos pensar que há algo que o desejo traz de indeterminável; e que há algo, ao mesmo tempo, que se se associa a partir do desejo. É indo por esta via do entre que pretendemos pensar as possibilidades e os limites das significações de um ato. Pois, quando Lacan diz que "é precisamente porque o desejo é articulado que ele não é articulável" (LACAN, 1995 [1966], p. 804), parece estar sempre implícita e inevitável a articulação a uma instância outra, em relação à qual precisa se associar ou agenciar, pela via do que Deleuze e Guattari (2010 [1972]) nos dirão, a partir de uma produção desejan- te. A respeito desta interlocução entre os autores, sugiro os trabalhos de Peixoto Junior (2004) e Judith Butler (1987, p. 184-217). Essa problemática, colocoa enquanto tal, não pretendendo resolvê-la, mas apostando na potência que pode oferecer a suspensão de sua definição.

\section{Referências}

BUTLER, Judith. Subjects of Desire: Hegelian Reflections in Twentieth-Century France. Nova York: Columbia University Press, 1987.

VIVEIROS DE CASTRO, Eduardo. Metafísicas canibais. São Paulo: Ubu Editora, 2018 [2009].

CHOAY, Françoise. A história e o método em urbanismo. In BRESCIANI, Stella (Org.). Imagens da cidade: séculos XIX e XX. São Paulo: Marco Zero, 1994, p. 1327.

COMITÊ INVISÍVEL (2014/2016). Crise e insurreição: aos nossos amigos. Tradução de Edições Antipáticas. São Paulo: n-1 edições, 2016 [2014]. 
DEBORD, Guy. Théorie de la Dérive. In Internationale Situationniste. Paris, 1958. Versão digital em disponível em https://monoskop.org/images/a/af/Intern ationale_situationniste_2.pdf.

DELEUZE, Gilles. Diferença e repetição. São Paulo: Editora Paz e Terra, 1968 [2011].

DELEUZE, Gilles; GUATTARI, Felix. O AntiÉdipo. São Paulo: Editora 34, 2010 [1972].

DERRIDA, Jacques. Gramatologia. São Paulo: Editora Perspectiva, 2013 [ 1967].

DERRIDA, Jacques. Cartão postal: de Sócrates a Freud. São Paulo: Civilização Brasileira, 2007 [1980].

FREUD, Sigmund. O Infamiliar. Belo Horizonte: Editora Autêntica, 2019 [1930].

GUATTARI, Felix. As Três Ecologias. $1^{a}$ versão eletrônica. Campinas: Papirus, 2001 [1989].

HAECKEL, Ernst. Generelle morphologie der organismen. Berlin: Georg Reimer Editor, 1866.

JAKOBSON, Roman. Linguística e comunicação. São Paulo: Ed. Cultrix, 2005 [1960].
JAKOBSON, Roman. (1976/1978). Six Lectures on Sound and Meaning. Cambridge, Mass.: The MIT Press, 1978 [1976].

JUNIOR, Carlos Augusto Peixoto. A lei do desejo e o desejo produtivo: transgressão da ordem ou afirmação da diferença? PHYSIS: Rev. Saúde Coletiva, Rio de Janeiro, v. 14, n. 1, p. 109-127, 2004.

LACAN, Jaques. O Seminário sobre "A Carta Roubada". In Escritos. Rio de Janeiro: Zahar, 1998 [1956].

LACAN, Jacques. L'Identification. Staferla, 2018 [1960-1961]. Versão digital disponível em http://staferla.free.fr/S9/S9\% 20L'IDENTIFICATION.pdf.

LACAN, Jacques. Comentário falado sobre a Verneinung de Freud. In Escritos. Rio de Janeiro: Editora Zahar, 1995 [1966].

LACAN, Jacques. L'Acte Psychanalytique. Staferla, 2018 [1967-1968]. Versão digital disponível em http://staferla.free.fr/S15/ S15\%20L'ACTE.pdf.

LATOUR, Bruno. Jamais fomos modernos. São Paulo: Editora 34, 1994 [1991].

LATOUR, Bruno. Políticas da natureza. Bauru, São Paulo: EDUSC, 2004 [1999].

NANCY, Jean-Luc. À L'Écoute. Paris: Editions Galilée, 2002. 
PALOMBINI, Analice de Lima. Vertigens de uma psicanálise a céu aberto: a cidade. In Contribuições do acompanhamento terapêutico à clínica na reforma psiquiátrica. Tese (Doutorado em Saúde Coletiva) Universidade Estadual do Rio de Janeiro, Rio de Janeiro, 2007.

PASSERON, René. Por uma Poïanálise. In SOUSA, Edson Luiz André; TESSLER, Elida; SLAVUTZKY, Abrão (Org.). A invenção da vida: arte e psicanálise. Porto Alegre: Artes e Ofícios, 2001.

SAUSSURE, Ferdinand de. Curso de Linguística Geral. Versão brasileira de 1970. Tradução de Antônio Chelini, José Paulo Paes e Izidoro Blikstein. São Paulo: Cultrix, 2012 [1970].

STENGERS, Isabelle; PIGNARRE, Philippe. La sorcellerie capitaliste. Paris: Editions La Découverte, 2005.

STENGERS, Isabelle. A proposição cosmopolítica. Revista do Instituto de Estudos Brasileiros, Brasil, n. 69, p. 442-464, 2018 [2007]. 